\title{
Impact of Joint Multiple Agricultural Technology Production of Beans on Household Nutrition Outcome in East Africa
}

\author{
Kachilei Levy ${ }^{1}$, Vincent Ngeno $^{2}$ \\ ${ }^{1}$ Department of Economics, Alupe University College, Busia, Kenya \\ ${ }^{2}$ Department of Agricultural Economics \& Resource Management, Moi University, Eldoret, Kenya
}

Email address:

kcvl14@gmail.com (K. Levy)

\section{To cite this article:}

Kachilei Levy, Vincent Ngeno. Impact of Joint Multiple Agricultural Technology Production of Beans on Household Nutrition Outcome in East Africa. American Journal of Engineering and Technology Management. Vol. 6, No. 2, 2021, pp. 16-23.

doi: 10.11648/j.ajetm.20210602.11

Received: January 12, 2021; Accepted: January 19, 2021; Published: April 29, 2021

\begin{abstract}
This study analyzes the impact of beans produced under joint multiple agricultural technologies (Improved beans variety, soil carbon management, integrated pest control, and use of compost manure) on nutrition outcome of stunting, underweight, and wasting in Kenya, Uganda, and Tanzania. Adoption of technologies in East Africa has been in isolation only focusing on single technologies. However, farmers typically adopt joint multiple agricultural technologies as complements or substitutes thus technologies to be adopted dependent on early technology choices. The objective of the study was to analyze the impact of the nutrition outcome variables in terms of stunting, wasting, and underweight for the best joint multiple agricultural technology combinations as a set of explanatory variables (z). This study adopts the multinomial endogenous switching regression model to correct for the selection bias and endogeneity. Results indicate that joint multiple agricultural technologies had a significant impact on the overall nutrition outcome in East Africa households. It is concluded that households in East Africa rarely use a single agricultural technology but rather a combination of different joint technologies in order to improve their nutrition outcome. The findings recommend that households should adopt joint multiple agricultural technologies rather than focusing on single technologies.
\end{abstract}

Keywords: Beans, Joint Multiple Agricultural Technologies, Nutrition Outcome, Stunting, Underweight and Wasting

\section{Introduction}

Agricultural technologies have driven a revolution of global agricultural production since the mid of 1960s [32]. According to Foresight (2011), substantial gains in production were achieved in Germany through the greater use of improved crops, soil carbon management, integrated pest control, and compost manure among other technologies [22]. However, this kind of technology model has not been fully applied in East Africa such as loss of biodiversity and soil fertility, stalinization, and water scarcity $[2 ; 42]$. There is established literature on how technologies affect the mean-variance of crop yield distribution, though much less is known about how technology adoption affects malnutrition [35; 17].

Nutritional deficiencies are the excesses, or imbalances in a person's intake of food energy and/or nutrients and it affects approximately 3 billion people around the world [57]. Malnutrition hinders the development of human potential in both social and economic development, especially in developing countries. Grassley and Eschiti (2008) explain that African countries have made fighting malnutrition a high priority especially through the adoption of technology in agriculture [25]. Deficiencies of the micronutrients, such as iron, zinc, and vitamin $\mathrm{A}$, are the most devastating among the East Africa countries [46]. Lukmanji et al., (2015) explain that nutrition outcome is the "terminal" variable that is directly influenced by anthropometric measures of underweight, stunting, and wasting [38]. It is indirectly affected by multiple agricultural technologies specifically, crop improved varieties, crop management biotechnology, and soil fertility enhancement.

Malnutrition cripple's both economic growth and development. Whereas, future global prosperity and effectiveness are directly linked to the ability of the health and development communities are in-adequately to respond to this challenge. In East Africa, nutritional deficiencies are responsible for $1.5-12 \%$ of the total Disability Adjusted Life Years (DALYs) (43). Alarming numbers concern malnutrition, which affects more than half of the female population [51]. 
Many people are suffering from multiple micronutrient deficiencies [42]; in Uganda over $50 \%$ of the households are estimated to be malnourished Joy et al., (2015) yet this is part of the Millennium Development Goals (MDG) indicators which are the priority when implementing by member countries [28].

Multiple agricultural technologies are aimed at reaching population groups who consume most of the staple food they produce and are often missed with other nutrition interventions (Khoury et al., 2014) like fortified foods [33]. It is anticipated by Muriithi and Matz, (2015) that adoption of multiple agricultural technologies such as improved crop varieties, crop biotechnology, pest control, and soil enhancement fertility can be a means by which malnourished rural households who may have less access to diverse meals, supplements, and fortified foods [44].

There is growing interest in the suggestion that multiple agricultural technologies delivered at the household and village level can improve nutrition outcomes [20]. The reviews of (Masset et al., 2013; Prucha, 1984; Wilson, 2015) are broadly consistent in their conclusions. [43, 48, 59].

According to IFPRI, (2015) East Africa countries have implemented the use of multiple agricultural technologies specifically, improved beans varieties, soil carbon management, integrated pest management, and use of compost manure [28]. In contrast to this implementation nothing has changed and the nutrition outcome of stunting, wasting, and underweight remain a salient problem facing the rural households [57 and 30]. Specifically, IFPRI (2015) explains how the Kenyan government through the ministry of agriculture rolled out crop management biotechnology program across the country to promote the use of biotechnology to reduce nutrition deficiencies but NBS (2016) survey shows that underweight was still affecting $50 \%$ of the children in rural households in East Africa [28, 46]. Kassie, (2018) states that the government of Tanzania promoted the use of crop improved varieties to improve farm productivity and crop nutrition but (IFPRI,2015) statistics indicate that the stunting was still a concern at $15 \%$ in Tanzania's rural households [30, 28]. Masset et al., (2013) state that soil fertility enhancement program in Uganda has enabled farmers to access the information on soil nutrients thus expected to enhance child wasting but Johnson et al., (2015) in her studies found out that majority of the rural household's recorded high wasting of $15 \%$ which is above the recommended $10 \%$ despite implementing this programs [43, 28].

Most of the previous studies have analyzed the impact assessment of a single technology like precision agriculture
[1], minimum tillage [29], and improved maize crop varieties [9; 58]. According to Alderman et al., (1987); Leroy and Frongillo, (2007) farmers rarely use a single agricultural technology but rather a combination of different joint technologies adopted in the farm over time $[5 ; 37]$. Therefore, this study was analyzing the impact of joint multiple agricultural technology combination that the household adopted on the nutrition outcome.

\section{Empirical Estimation}

This section outlines the theory behind the study and the econometric estimation strategy used in the paper where descriptive statistics and econometric analyses are employed. The combination of descriptive and analytical techniques, combined with the other research delivery mechanisms were used to analyze the impact of adopting joint multiple agricultural technologies in the East Africa household nutrition status.

\subsection{Random Utility Theory}

We conceptualized that the decision to adopt a combination of multiple agricultural technologies (MATs) is modeled in consumer theory, specifically a random utility framework. Following Kassie et al., (2014, 2018) we consider the latent model $\left(\mathrm{U}^{*}{ }_{\mathrm{jit}}\right)$ below which describes the $\mathrm{i}^{\text {th }}$ farmer's behavior in adopting MATs $j(j=1, \ldots 4)$ at time $t$ over any alternative MATs combination;

Where $X_{j i t}$ is a vector of observed exogenous covariates that represents household and farm level characteristics, institutional support services, household assets, demographics, district dummies, plot characteristics, geographical variables, and weather shocks. $\alpha$ and $\omega$ are vectors of parameters to be estimated, and $\varepsilon_{\mathrm{jit}}$ is the random error term $[30 ; 31]$.

In the $1^{\text {st }}$ stage, the estimation of the multinomial logit model (MNLS) model (which is not presented in this paper) could be inconsistent due to the correlation of unobserved factors with explanatory variables. To address this, we followed [45] and [56] approach where the means $\overline{\mathrm{X}}_{\mathrm{ji}}$ of all time-varying covariates were included as additional covariates in the MNLS model. Unlike the adoption decision which is observable, the utility derived from the adoption of MATs is unobservable. Therefore, Eq. (1) entails that the ith farmer adopted a combination of MATs $\mathrm{j}$ to maximize expected benefits if the technology provides greater utility than an alternative combination $\mathrm{m}, \mathrm{m} \neq \mathrm{j}$; e.g., if $\mathrm{T}_{\mathrm{jit}}$ $=\max _{\mathrm{m} \neq 1}\left(U_{m i t}^{*}-U_{j i t}^{*}\right)<0$, assuming that $\varepsilon_{\mathrm{jit}}$ are independent and identically Gumbel distributed [9].

$$
U_{j i t}^{*}{ }_{m \neq j}^{m}=\alpha_{j} X_{j i t}+\omega_{j} \bar{X}_{j i}+\varepsilon_{j i t} \text { with } U\left\{\begin{array}{c}
1 \text { if } U_{j i t}^{*}>\max _{m \neq 1}\left(U_{m i t}^{*}\right) \text { or } \tau_{1 i t}<0 \\
\vdots \\
\text { if } U_{j i t}^{*}>\max _{m \neq j}\left(U_{m i t}^{*}\right) \text { or } \tau_{j i t}<0
\end{array} \quad\right. \text { for all }
$$

\subsection{Multinomial Endogenous Switching Regression (MESR)}

In the MESR $2^{\text {nd }}$ stage, the relationship between the nutrition outcome variables in terms of stunting, wasting, and underweight for the best joint multiple agricultural technology combinations as a set of explanatory variables $(\mathrm{z})$.

$\mathrm{TC} 1$ is a joint combination of improved beans variety, soil carbon management, and compost manure, $\mathrm{j}=1$;

TC2 is a joint combination of improved beans variety, soil 
carbon management, and integrated pest management, $\mathrm{j}=2$;

TC3 is a joint combination of soil carbon management, integrated pest management, and compost manure, $\mathrm{j}=3$;

TC4 is a joint combination of improved beans, integrated pest management, and compost manure, $\mathrm{j}=4$.

The impact equation to represent nutrition outcome implication in each possible regime (j) was given as:

$$
\left\{\begin{array}{c}
\text { Regime } 1: y_{1 i t}=\beta_{1} z_{1 i t}+\vartheta_{1} \overline{\mathrm{Z}}_{1 i}+\mu_{1 i t} \text { if } U=1 \\
\vdots \vdots \\
\text { Regime J: } y_{j i t}=\beta_{j} z_{j i t}+\vartheta_{j} \overline{\mathrm{Z}}_{j i}+\mu_{j i t} \text { if } U=j
\end{array} j=2,3 \ldots 4\right.
$$

where $y_{\text {jit }}$ are the nutrition outcome variables of the farmer household $i$ in regime $j$ at time $t$ and the error terms $\left(\mu_{\mathrm{jit}}\right.$ 's) are distributed with $E\left(\mu_{\mathrm{jit}} / \mathrm{X}, \mathrm{z}\right)=0$ and $\operatorname{var}\left(\mu_{\mathrm{jit}} / \mathrm{X}, \mathrm{z}\right)=\delta_{\mathrm{j}}^{2} \cdot \mathrm{y}_{\mathrm{jit}}$ 's are observed if only one of the possible adoption combinations is used.

The means of all time-varying variables $\bar{Z}$ in Eq. (2) were added as additional regressors in order to get consistent estimates. This approach can minimize the problem of unobserved heterogeneity $[46 ; 56]$. The error term $\left(\mu_{\mathrm{jit}}\right)$ is comprised of unobserved individual effects $\left(\mathrm{c}_{\mathrm{i}}\right)$ and a random error term $\left(\mu_{\mathrm{it}}\right)$. Therefore, OLS estimates in Eq. (2) is biased if $\varepsilon_{\mathrm{jit}}$ 's and $\mu_{\mathrm{jit}}$ 's are not independent. Consistent estimation of $\beta_{\mathrm{j}}$ and $v_{\mathrm{j}}$ required the inclusion of the selection correction terms of the alternative choices in Eq. (2). In the multinomial choice setting, there are $j-1$ selection correction terms, one for each alternative adoption combination. Following [22] and $[22,31]$, the MESR with consistent estimates was specified as follows:

$$
\left\{\begin{array}{c}
\text { Regime 1: } y_{1 i t}=\beta_{1} z_{1 i t}+\sigma_{1} \hat{\lambda}_{1 i}+\vartheta_{1} \overline{\mathrm{Z}}_{1 i}+\mu_{1 i t} \text { if } U=1 \\
\quad \vdots \vdots \\
\text { Regime J: } y_{j i t}=\beta_{j} z_{j i t}+\sigma_{j} \hat{\lambda}_{j i}+\vartheta_{j} \overline{\mathrm{Z}}_{j i}+\mu_{j i t} \text { if } U=j
\end{array} j=\right.
$$

where $\mu_{\mathrm{jit}}$ was the error term with an expected value of zero, $\delta$ was covariance between $\varepsilon_{\mathrm{jit}}$ 's and $\mu_{\mathrm{jit}}$ 's, $\hat{\lambda}_{j i t}$ was the inverse Mills ratio computed from estimated probabilities in Eq. (2) as follows:

$$
\hat{\lambda}_{j i t}=\sum_{m \neq j}^{j} \rho_{j}\left[\frac{\widehat{\mathrm{P}}_{m i} \operatorname{In}\left(\widehat{\mathrm{P}}_{m i}\right)}{1-\widehat{\mathrm{P}}_{m i}}+\mathrm{I} n\left(\widehat{\mathrm{P}}_{j i t}\right)\right]
$$

At this point, $\rho$ was the correlation between $\varepsilon_{\mathrm{jit}}$ 's and $\mu_{\mathrm{jit}}$ 's. Standard errors in Eq. (3) was bootstrapped to account for the heteroscedasticity arising from the generated regressors due to the two-stage estimation procedure.

Hence, households can choose to adopt modern technologies if they understand their inherent characteristics or potential benefits [6]; [39]; [58] through early experience [4;
37]. We performed correlation analysis and a simple falsification test [15]. Many other empirical studies such as [1]; [30] have used similar variables in impact evaluation as instruments. According to Kassie, et al., (2018), this approach will not only correct for selection bias due to unobserved heterogeneity but also controls for selection bias due to observed heterogeneity [31].

\section{Results}

The selected area of study was East Africa countries namely Kenya, Tanzania, and Uganda. Data used for Multi-agricultural technology is a unique primary household and community level survey data from Kenya, Tanzania, and Uganda. The survey started in the planting season of 2007/2008 and the data collection took place in selected districts in Kenya, Tanzania, and Uganda through to $2016 / 2017$ season. The survey was conducted by IFRI in collaboration with Kenya Agricultural Research Institute (KARI), Kenya; Makerere University, Uganda; and Maruku Agricultural Research Institute (MARI), Tanzania. The survey was designed to collect valuable information on several household compositions, health status, agricultural technology, and its characteristics. A total of 1,500 households was analyzed.

Joint adoption of multiple agricultural technologies led to four combinations of technologies from which the household can choose (Table 1). Combinations of technologies take the highest best combination so as to take care of collinearity.

Where, Improved beans crops $=1$, soil carbon management $=2$, integrated pest control $=3$, compost manure $=4$.

Therefore, the best joint technologies are;

*TC1 $=$ Joint Technology of $(1,2,4)$

$* \mathrm{TC} 2=$ Joint Technology of $(1,2,3)$

*TC3 = Joint Technology of $(2,3,4)$

*TC4 = Joint Technology of $(1,3,4)$

Table 1. Descriptive statistics of the technology adopted.

\begin{tabular}{lll}
\hline Variable & Description of joint technology & Mean \\
\hline TC1 & 1= Joint Improved beans crops, soil carbon management, compost manure & Std. Dev. \\
TC2 & 1= Joint Improved beans crops, soil carbon management, integrated pest control & 1.84 \\
TC3 & 1= Joint of soil carbon management, integrated pest control, compost manure. & 1.201333 \\
TC4 & 1= Joint Improved beans crops, integrated pest control, compost manure & 1.028 \\
IMR & Inverse mills ratio & 1.100667 \\
\hline
\end{tabular}

As shown in Table 1, 84\% of the household adopted joint improved beans crops, soil carbon management, and compost manure combination while those who adopted Joint TC2, TC3, and TC4 had a mean of 1.20133, 1.028, and 1.100667 respectively. 
Table 2. Frequency of technology adopted in Kenya, Uganda, and Tanzania.

\begin{tabular}{lllll}
\hline Technologies & Country of Kenya & Project Tanzania & Uganda & Total \\
\hline BEANS IMPROVED VARIETY & $132(23.91 \%)$ & $216(39.13 \%)$ & $204(36.95 \%)$ & $560(37.8 \%)$ \\
SOIL CARBON MANAGEMENT & $120(28.03 \%)$ & $172(40.18 \%)$ & $136(31.77 \%)$ & $438(29.53 \%)$ \\
COMPOST MANURE & $138(51.49 \%)$ & $60(22.38 \%)$ & $70(26.11 \%)$ & $278(18.86 \%)$ \\
INTEGRATED PEST CONTROL & $110(43.65 \%)$ & $52(20.63 \%)$ & $90(35.71 \%)$ & $254(16.8 \%)$ \\
Total & 500 & 500 & 500 & 1500 \\
\hline
\end{tabular}

Improved bean varieties were the most adopted technology at 37.8 percent. Apart from this technology being the entry to the adoption of multiply agricultural technologies for this program, they were also provided at subsidies prices [21]. Tanzania was the leading adopter of improved beans variety at 39.13 percent, followed by Uganda at 36.95 percent then Kenya at 23.91 percent. Tanzania was leading because they enacted the new seeds act in 2003 with subsequent regulation in 2006 and the plant breeder right act of 2010 that influence change and adoption of the new seed legislation [21].

Compost manure utilization was highly adopted in Kenya (51.49 percent) followed by Uganda (26.11 percent and then Tanzania at 22.38 percent. In Kenya WHO (2002) stated that farmers using organic fertilizer for beans planting had increased by 56 percent better than the other East African countries as from 2002 the argument supported by Waterlow and Payne (1975) indicating that other Ugandan and Tanzania farmers have for the longest time going about the issue of compost manure wrongly, with many collecting animal waste and spreading it on the field immediately [57, 55].

Soil carbon management was adopted the most in Tanzania (40.18percent). As put by USAID (2017) the project 'Development of soil carbon map based on NAFORMA and non- NAFORMA datasets in Tanzania was aimed to map the organic carbon content of Tanzania, this made sure Tanzania becomes the first-ever comprehensive soil inventory in East Africa [53].

Integrated pest control was the least adopted technology in East Africa with a 16.8 percent adoption rate. Kenya had the highest adoption rate at 43.65 percent and Uganda 35 percent while Tanzania was least at 20.06 percent. Wang and Ni (1995) explain that east Africa has not enhanced both export market access and food safety thus a low rate of intergraded pest management [54]. While UBOS (2001) explains that pesticides risk reduction through registration of less hazardous pesticide and the promotion of non-chemical pest and disease control approach [52].

Table 3. The frequency of technology adoption determine by the level of education.

\begin{tabular}{llllll}
\hline Technologies & Level of education None & Of the Primary & Household Secondary & Head Tertiary & Total \\
\hline Beans improved variety & $30(5.12 \%)$ & $178(30.37 \%)$ & $320(54.60 \%)$ & $58(9.89 \%)$ & 586 \\
Soil carbon management & $32(7.44 \%)$ & $146(33.95 \%)$ & $224(52.09 \%)$ & $28(6.51 \%)$ & 430 \\
Compost manure & $20(7.09 \%)$ & $98(34.75 \%)$ & $156(55.31 \%)$ & $8(2.28 \%)$ & 282 \\
Integrated pest control & $17(8.41 \%)$ & $59(29.20 \%)$ & $120(59.40 \%)$ & $6(2.97 \%)$ & 202 \\
Total & 99 & 481 & 820 & 100 & 1500 \\
\hline
\end{tabular}

A household headed by a member with no education had the least adoption rate of improved bean variety at 5.12 percent, with a household headed by a secondary school leaver leading in the adoption of improved beans variety at $54.6 \%$. Smith and Blundell (1986) in their study supported the idea that lack of education brings upon lack of adequate information about technologies, and price risks, and therefore low adoption rate to these technologies [49].

Johnson et al., (2015) found out that many secondary school leavers in East Africa would access the internet and are mostly active in training and hence their perceived attributes of innovation that then to increase their percentage difference on the rate of adoption of technology [28].

It is also noted that households headed by the secondary school leaver were leading adopters of the four technologies implemented by $52.09 \%$ in soil carbon management, $55.31 \%$ in compost manure, and $59.4 \%$ in intergraded pest control.

Abdulas and Regmi (2000) emphasized that secondary school leavers are easily reachable and generally have a high interest in farming [1]. This enhances the understanding of instruction given and also improves the farmer's level of participation in agricultural activities. According to to Beck et al., (2007), this is so because of the training they attended and they are pro-active which enables them to access information needed to decide to use innovation and practices new technology [8]. It also increases their managerial competence and therefore enhances their ability to diagnose, assess, comprehend, and respond to financial and production problems especially in integrated pest control [11]. It was also noted that most of the secondary school leavers were members of co-operative societies, focus group discussion, and opinion leaders in the society, this boost their technologies adoption rate. Malapilt et al., (2013) in their assessment of farmers' knowledge on compost manure indicate that about 50 percent of farmers in East Africa utilize compost manure since it has been an old technology and the materials were readily available [41].

A household headed by a member with tertiary education had a low adoption rate to all the technologies with improved beans variety at 9.8 percent, soil carbon management at 6.5 percent, compost manure at 2.28 percent, and integrated pest control at 2.97 percent. These results are supported by Magnus (1982) that primary school leavers are trained through hands-on experience in East Africa and are not required to 
have a college degree [40].

It was found out that household headed by a member with tertiary education was doing commercial farming instead of subsistence farming thus it was easier to use chemicals to control. They also utilize inorganic fertilizers from agro vet instead of practicing compost manure. Cunia and Briggs (1984) mention that large farms are owned by the learned and wealthy cannot be considered linear replicas of small ones. Incentives to use inputs vary with production scale that is large farms use different technologies than small farms thus the use of compost manure and integrated pest control was low at $2.97 \%$ and $2.28 \%$ respectively because it could not fit large scale farming practice by the household headed by members with tertiary education [14]. In agreement WHO (2002), found out that associates and bachelor's degree graduates in agricultural courses took up farming as their careers [57]. This finding is in agreement with Avery (1977) that the relationship between the level of farmers' education with the agricultural course was positive, continuous, and significant. A similar result was also supported by Cheng et al., (2013) on their agricultural input results $[4,12]$.

Correlation analysis

Table 4 shows the result of the correlation analysis between the nutrition outcome of stunting (zht), underweight (zumwt) and wasting (zwh) and the joint technology adoption of TC1, TC2, TC3 and TC4.

Joint agriculture technology affects health and nutrition in tangible ways. It is a source of energy and nutrients and increased agricultural productivity leads to better nutrition.

Table 4. Correlation between nutrition outcome and joint technology.

\begin{tabular}{llll}
\hline (obs=1,500) & & & \\
\hline & ZUnWt & ZwH & Zht \\
\hline TC1 & -0.0338 & -0.0415 & -0.0361 \\
TC2 & -0.0002 & -0.0232 & -0.0057 \\
TC3 & -0.0591 & -0.0990 & -0.0779 \\
TC4 & -0.0447 & -0.0120 & -0.0337 \\
\hline
\end{tabular}

The result shows a general negative relationship between joint technologies $\mathrm{TC} 1, \mathrm{TC} 2, \mathrm{TC} 3$, and TC4 and the nutrition outcome of stunting wasting, and underweight. These findings are supported by Baltagi, (2011) that indicators of the level of agricultural technology adoption have a strong and significant negative association with indicators of nutrition outcome among households, a result suggesting that increment of agricultural technology adoption can be a powerful tool to reduce malnutrition across the vast majority of the population in East Africa [7].

Econometrics Results

Table 5 presents the result of the multinomial endogenous switching regression relationship between the nutrition outcome variables in terms of stunting $(\mathrm{Zht})$, underweight (zumwt), and wasting (zwh) and the joint agricultural multiple technology adoption of TC1, TC2, TC3, and TC4 as a set of explanatory variables. The inverse mills ration (I. M) was computed from estimated probabilities (not included in the paper).
The joint agricultural technologies TC1 (improved beans variety, soil carbon management, and compost manure) was found to have a negative significant relationship to stunting (Zht), wasting $(\mathrm{ZwH})$ and underweight (ZUnWt) Table 5.

With a one percent increase in the adoption of joint TC1, the prevalence of stunting reduces by $17.4 \%$, wasting $15.4 \%$, and underweight by $16.8 \%$. The reduction of stunting, wasting, and underweight is a sign of better nutritional outcome. The utilization of dietary diversity due to the variety of the improved beans explained by Chang'al (2009) has a major implication for the reduction of stunting for rural households [11]. Applying the soil carbon management on beans production had a greater impact on household wasting as per the studies of Behrman and Deolalikar (1988) supported by the findings of Hamshire et al., (2009) that soil carbon management plays a very important role in reducing stunting through strengthening food value chains that aim to improve the availability of nutrients components [26].

Table 5. Multinomial Endogenous Switching Regression Analysis.

\begin{tabular}{llll}
\hline \multirow{2}{*}{ VARIABLES } & $\mathbf{( 1 )}$ & $\mathbf{( 2 )}$ & $\mathbf{( 3 )}$ \\
\cline { 2 - 4 } & $\mathbf{Z h t}$ & $\mathbf{Z w H}$ & $\mathbf{Z U n W t}$ \\
\hline TC1 & $-0.174 * * *$ & $-0.154 * * *$ & $-0.168 * * *$ \\
& $(0.0564)$ & $(0.0417)$ & $(0.0404)$ \\
TC2 & 0.0920 & $-0.144 * *$ & $-0.151 * * *$ \\
& $(0.0769)$ & $(0.0569)$ & $(0.0551)$ \\
TC4 & $-0.156 * * *$ & $-0.0807 *$ & 0.0625 \\
& $(0.0563)$ & $(0.0417)$ & $(0.0403)$ \\
TC3 & $-0.258 * * *$ & $-0.241 * * *$ & $-0.253 * * *$ \\
& $(0.0552)$ & $(0.0408)$ & $(0.0395)$ \\
IMR & 0.0278 & 0.0246 & 0.0315 \\
& $(0.0281)$ & $(0.0208)$ & $(0.0201)$ \\
Constant & $0.373 * * *$ & $0.818 * * *$ & $0.633 * * *$ \\
& $(0.0768)$ & $(0.0569)$ & $(0.0550)$ \\
Observations & 1,490 & 1,490 & 1,490 \\
R-squared & 0.024 & 0.112 & 0.033 \\
\hline
\end{tabular}

Standard errors in parentheses

$* * * \mathrm{p}<0.01, * * \mathrm{p}<0.05, * \mathrm{p}<0.1$

Gottleib (2004) also pointed out that using compost manure in beans production are sources of plant nutrients hence supply the basic food nutrients that improve underweight in the household through adequate dietary intake [23]. According to [24], commercial fertilizers supply all the basic nutrients that beans need to thrive but [34] reported that an increase in bean's nutrients yield is because of the use of compost manure rather than commercial fertilizer. This was also enhanced by [49] that the total fresh weight results from beans produced using compost manure had a positive impact on household wasting and stunting status. Therefore, joint TC1 improved nutrition outcomes.

The household that adopted the joint multiple agricultural technology TC2 had a negative significant impact on wasting with the coefficient of 0.144 and underweight coefficient of 0.151. A one percent increase in the adoption of joint improved beans, soil carbon management, and integrated pest control technology leads to a $14.4 \%$ percent reduction of 
wasting and a $15.1 \%$ reduction in the underweight prevalence.

Cooley and Prescott (1973) underline that integrated pest management is an ecosystem approach that combines different management strategies and practices to produce healthy beans and minimize the use of pesticides [13]. Thus, EHNRI (2000) stated that with the joint agricultural technology these healthy beans are produced then to address the nutrients deficiency and household wasting [20]. While Gragnolita and Marini (2003) explained that iron-bio fortified beans reduce the underweight as that the household health is so integral for their own wellbeing as well as their agricultural activities [24]. Johnson et al., (2015) explain that cover crops improve soil quality through increasing biomass by improving soil aggregates and stability [25]. Similarly, green manuring increases the biomass returned to the soil thus enhancing improved beans production with high nutrient content to managed stunting.

Krebs-Smith et al., (1995) noted that improved beans variety improves in complementary technology like soil carbon management thus decreases the burden of underweight [34]. Malapi et al., (2013) concluded in their findings that the high iron beans also known as Nyota variety grown in Kenya are a sustainable solution to tackling wasting [41]. The combination of soil carbon management and integrated pest control on the production of improved variety ensured the control of wasting and underweight [47].

The households which adopted the joint multiple agricultural technology TC3 negatively affected stunting at coefficient 0.258 , Wasting at 0.241 , and underweight at 0.253 . A one percent increase in the adoption of joint TC3 leads to a $25.8 \%$ decrease in the household stunting Z-scores. The use of integrated pest management utilizes biological control rather than chemical thus making it sustainable and resistant to disease control in crops without losing the nutrients value [5] Therefore, being reach in nutrients value [10] explain how it improves house stunting in terms of diets, quality, and quantity through important vitamins and minerals linked to growth, development, and immune function. This is supported by Cuniana and Briggs (1984) emphasizing policies especially on soil carbon management which aimed at accelerating crops development which is generally effective at reducing underweight [14]. With a $1 \%$ increase in the adoption of joint TC3 agricultural technology especially compost manure, the household reduce the wasting Z-scores by $24.1 \%$ holding the other factors constant. [6] in his study concluded that there was an increase in foliar diseases after they stopped using composted manures and a decrease in the vegetable yield due to the less nitrogen and phosphorus nutrients which was filtered from compost. Poor access to good vegetable yields and particularly healthy foods contributes to wasting [20]. WHO (2002) stated that vegetable field through compost manure can both directly compromised diets and indirectly impacts on food production of a household which causes the household malnutrition on wasting Z-scores [57].

The joint agricultural multiple technology adoption TC4 was found to significantly affecting stunting and wasting negatively with coefficients of 0.156 and 0.807 respectively. TC4 was the joint combination of using compost manure and integrated pest control on improved beans variety. Increasing the adoption of joint TC4 by one percent the household stunting will reduce by $15.6 \% \mathrm{Z}$-scores holding the other factors constant. Adopting joint TC4 by $1 \%$ will improve nutrition outcomes by reducing wasting by $8.07 \%$ holding the other factors constant.

West (2000) explains that though it may appear to be a paradox, multiple agricultural productions through technology is often associated with underweight, stunting, and wasting. The higher cost of nutritious foods, the hardship of living with food insecurity, and the adoption of food scarcity in East Africa have a higher risk of nutrition deficiency [54].

Stanek and Koch (1985) confirm that one way of reducing stunting would be to improve the crops through the breeding of new varieties that have better yields and nutrient content [50]. Crop bio-fortification of different varieties as explained by EHNRI (2000) offers sustainable and increased morbidity especially improved beans variety thus impaired development of underweight, wasting, and stunted household [20]. Drichoutis et al., (2006) proposed to deal with the issue through the promotion of improved soil carbon management practices which then enhance stunting [17].

\section{Conclusion and Recommendation}

It is concluded that households in East Africa rarely use a single agricultural technology but rather a combination of different joint technologies in order to improve their nutrition outcome. The study adopted the multinomial endogenous switching regression to analyze the relationship between the nutrition outcome and the technology adopted using panel data so as to correct for selection bias and endogeneity originating from both observed and unobserved heterogeneity.

When the household utilized the joint multiple agricultural technology TC1, TC2, TC3, and TC4 the household nutrition outcome of underweight, stunting, and wasting reduces significantly. Thus, this joint multiple agricultural technology combination has helped improve the nutrition status of the East Africa households who adopted joint multiple agricultural technologies.

These findings provide the East Africa countries with a holistic picture of the gap in access to the driver of nutrition outcome that is critical for the formation of a more informed, evidence-based, and balanced multi agricultural strategy against malnutrition.

It is recommended that an informed policy formulation that focuses on the joint multiple agricultural technology adoption efforts be strengthened and prioritize since it will improve household nutrition outcomes.

\section{Acknowledgements}

This research was supported by African Economic Research Consortium (AERC) Ph. D. research thematic grants. 


\section{References}

[1] Abdulai A., Regmi P. P. (2000) 'Estimating Labor Supply of Farm Households under Non Separability: Empirical Evidence from Nepal', Agricultural Economics, 22 (3): 309-20.

[2] Abonazel, M. R. (2009). Some Properties of Random Coefficients Regression Estimators. Institute of Statistical Studies and Research. Cairo University.

[3] Abonazel, M. R. (2014). Some estimation methods for dynamic panel data models. Institute of Statistical Studies and Research. Agriculture Organization of the United Nations, Rome.

[4] Alcacer, J., Chung, W., Hawk, A., Pacheco-de-Almeida, G. (2013). Applying random coefficient models to strategy research: testing for firm heterogeneity, predicting firm-specific coefficients, and estimating Strategy Trade-Offs. Working Paper, No. 14-022. Harvard Business School Unit.

[5] Alderman H. 1987. Cooperative dairy development in Karnataka, India: An assessment. Research Report 64. IFPRI (International Food Policy Research Institute), Washington, DC, USA. $60 \mathrm{pp}$.

[6] Anríquez G., Stamoulis K. (2007) 'Rural Development and Poverty Reduction: Is Agriculture Still the Key?' ESA FAO Working Paper 07-02. Approach. Food Security 6 (2): 217-230.

[7] Baltagi, B. H. (2011). Econometrics. 5th ed. Berlin: Springer-Verlag Berlin Heidelberg.

[8] Beck, N., Katz, J. N. (2007). Random coefficient models for time-series-cross-section data: Monte Carlo experiments. Political Analysis 15 (2): 182-195.

[9] Bodhlyera, O., Zewotir, T., Ramroop, S. (2014). Random coefficient model for changes in viscosity in dissolving pulp. Wood Research 59 (4): 571-582.

[10] Bouis H. E. and Haddad L. J. 1990. Agricultural commercialisation, nutrition and the rural poor: A study of Philippine farm households. Lynne Rienner Publishers, Boulder, Colorado, USA.

[11] Chang'aL.(2009) 'SeasonalRainfallForecastinginTanzania'. PaperpresentedattheWorkshopon

High-ImpactWeatherPredictabilityandInformationSystemforA fricaandAMMA-THORPEX Forecastor's Handbook, ICTP, Trieste, Italy, 5-8 October.

[12] Cheng, J., Yue, R. X., Liu, X. (2013). Optimal Designs for Random Coefficient Regression Models with Heteroscedastic Errors. Communications in Statistics-Theory and Methods 42 (15): 2798-2809.

[13] Cooley, T. F., Prescott, E. C. (1973). Systematic (non-random) variation models: varying parameter regression: a theory and some applications. Annals of Economic and Social Measurement 2 (4): 463-473.

[14] Cunia, T. and Briggs, R. D. (1984). Forcing additivity of biomass tables: some empirical results. Canadian Journal of Forest Research 14: 376-384.

[15] DeSerpa, A. (1971). "A theory of the economics of time". The Economic Journal, 81 (324).

[16] Dielman, T. E. (2008). Chapter 3: Seemingly unrelated regressions. Pooled cross-sectional and time series data analysis (pp. 29-47). New York: Marcel Dekker, Inc. PCPFS Research Digest, 2 (1).

[17] Drichoutis, A. C., Lazaridis, P., and Nayga, R. M., Jr. (2006). "Nutrition knowledge and consumer use of nutritional food labels". European Review of Agricultural Economics, 32 (1): 93-118.

[18] Dwivedi, T. D. and Srivastava, V. K. (1978). Optimality of least squares in the seemingly unrelated regression equation model. Journal of Econometrics 7: 391-395.

[19] Ehlers, T. (2010). Silent looms: Women and production in a Guatemalan town. Austin, TX: University of Texas Press.

[20] EHNRI (Ethiopian Health and Nutrition Research Institute). 2000. Food composition tables for use in Ethiopia: Part III. EHNRI, Addis Ababa, Ethiopia.

[21] FAO (2018). A systematic analysis for the global burden of disease study 2013. The Lancet, 384 (9945), 766-781.

[22] Forster, M. (2001). "The meaning of death: Some numerical simulations of a model of healthy and unhealthy consumption". Journal of Health Economics, 20 (4): 613638.

[23] Gottlieb, A. (2004). The afterlife is where we come from: The culture of infancy in West Africa. Chicago, IL: University of Chicago Press.

[24] Gragnolati, M., \& Marini, A. (2003). Health and poverty in Guatemala (World Bank policy research working paper 2966). Washington, DC: The World Bank.

[25] Grassley, J., \& Eschiti, V. (2008). Grandmother breastfeeding support: What do mothers need and want? Birth, 35 (4), 329335. doi: 10.1111/j.1523-536x.2008.00260.x

[26] Hampshire, K., Casiday, R., Kilpatrick, K., \& Panter-Brick, C. (2009). The social context of childcare practices and child malnutrition in Niger's recent food crisis. Disasters, 33 (1), 132-151. doi: 10.1111/j.1467-7717.2008.01066.x.

[27] IFPRI (2015). Individual Dietary Diversity. Nutrition and Consumer Protection Division.

[28] Johnson, N., Guedenet, H., \& Saltzman, A. (2015). What will it take for biofortification to have impact on the ground? Theories of change for three crop-country combinations. IFPRI discussion paper. Washington: International Food Policy Research Institute.

[29] Judge, G. G., Griffiths, W. E, Hill, R. C. and Lütkepohl, H. (1985). Chapter 12: Disturbance-related sets of regression equations. The Theory and Practice of Econometrics (2nd ed., pp. 465-514). New York: Wiley.

[30] Kassie, M., M. Jaleta., and A. Mattei. 2014. Evaluating the Impact of Improved Maize Journal of the American Statistical Association 63 (324): 1180-1200.

[31] Kassie, J. R. 2018 "Multivariate Error Components Analysis of Linear and Nonlinear Regression Models by Maximum Likelihood." J. Econometrics.

[32] Kennedy, G., T. Ballard., and M. C. Dop. 2013. Guidelines for Measuring Household.

[33] Khoury, C. K., Bjorkman, A. D., Dempewolf, H., Ramirez-Villegas, J., Guarino, L., Jarvis, A., et al. (2014). Increasing homogeneity in global good supplies and the implications for food security. 
[34] Kim, S.-Y., Nayga, R. M., Jr., and Capps, O., Jr. (2001). "Food label use, self selectivity, and diet quality". The Journal of Consumer Affairs, 35 (2): 346- 363.

[35] Kim, S.-Y., Nayga, R. M., Jr., and Capps, O., Jr. (2003). "Health knowledge and consumer use of nutritional labels: The issue revisited". Agricultural and Resource Economics Review, 30 (1): 10-19.

[36] Koppmair, S., M. Kassie, and M. Qaim. 2017. Farm Production, Market Access and Dietary.

[37] Leroy, J. L., \& Frongillo, E. A. (2007). Can interventions to promote animal production ameliorate undernutrition? The Journal of Nutrition, 137 (10), 2311-2316.

[38] Lukmanji, Z., E. Hertzmark., N. Mlingi., V. Assey., G. Ndossi, and W. Fawzi, 2008.

[39] Maeshiro, A. (2016). New evidence on the small properties of estimators of SUR models with autocorrelated disturbances. Journal of Econometrics 12: 177-187.

[40] Magnus, J. R. "Multivariate Error Components Analysis ofLinear and Nonlinear Regression Models by Maximum Likelihood." J. Econometrics 19 (August 1982): 239-85.

[41] Malapit, H. J. L., \& Quisumbing, A. R. (2013). What dimensions of women's empowerment in agriculture matter for nutrition-related practices and outcomes in Ghana? IFPRI discussion paper. Washington: International Food Policy Research Institute.

[42] Masset, E., Haddad, L., Cornelius, A., \& Isaza-Castro, J. (2012). Effectiveness of agricultural interventions that aim to improve nutritional status of children: BMJ, 344, d8222.

[43] Masset, E., L. Haddad, A. Cornelius., and J. Isaza-Castro. 2013. Effectiveness of Agricultural.

[44] Muriithi, B. W., and J. A. Matz. 2015. Welfare Effects of Vegetable Commercialization.

[45] Mundlak, S., J. H. Rah., J. D. Sugimoto., F. F. Roos., K. Kraemer., and R. E. Black. 2013.

[46] NBS (2016). Human Nutrition Collaborative Support Program Kenya Project, Office of Nutrition, USAID, Washington, DC, USA.

[47] Nisbett, N., Gillespie, S., Haddad, L., \& Harris, J. (2014). Why worry about the politics of childhood undernutrition? World Development, 64, 420-433.

[48] Prucha, I. R. (1984). On the asymptotic efficiency of feasible Aitken estimators for seemingly unrelated regression models with error components. Econometrica 52 (1): 203-207.

[49] Smith, R. J., and R. W. Blundell. 1986. An Exogeneity Test for a Simultaneous Equation Tobit.

[50] Stanek, E. J., III and Koch, G. G. (1985). The equivalence of parameter estimates from growth curve models and seemingly unrelated regression models. The American Statistician 39 (2): $149-152$.

[51] Statistical Society: Series A (Statistics in Society) 175 (2): 587-617.

[52] UBOS (2001) Discussion Paper, 70. International Food Policy Research Institute.

[53] USAID (2017). International in association with the Crawford Fund for International Agricultural Research, 2014. USA (34): 10657-10662.

[54] Wang, J. and D. Ni. 1995. A comparative study of the ability of fish to catch mosquito larvae. In K. T. Mackey (ed.) 1995. Rice - Fish Culture in china. International development research centre (IDRC) Ottawa, Canada.

[55] Waterlow, J. C. and P. R. Payne. 1975. "The protein gap." Nature. 258: 113-117.

[56] Wooldrige, A. (2010). Estimators for seemingly unrelated regression equations: some exact finite sample results. Journal of the American Statistical Association 58 (304): 977-992.

[57] WHO (2016). Expert Consultation on Diet, Nutrition, and the Prevention of Chronic Diseases. World Health Organization. Geneva.

[58] Wild, S., G. Roglic, Green A., R. Sicree, and H. King. 2004. "Global prevalence of diabetes: estimates for 2000 and projections for 2030." Diabetes Care. 27: 1047-1053.

[59] Wilson, B. K. (2015). Simultaneity and its impact on ecological regression applications. Biometrics 41: 435-445.

[60] World Bank. 2004. Repositioning Nutrition as Central to Development: A Strategy for LargeScale Action. Washington DC. 